\title{
Nanoscale Thermosensitive Hydrogel Scaffolds Promote the Chondrogenic Differentiation of Dental Pulp Stem and Progenitor Cells: A Minimally Invasive Approach for Cartilage Regeneration
}

This article was published in the following Dove Press journal:

International Journal of Nanomedicine

Wael Talaat, (D) ${ }^{1-3}$ Smriti Aryal AC, (D) ${ }^{1,2}$ Sausan Al Kawas, (D) ${ }^{1,2}$ AB

Rani Samsudin, ${ }^{1,2}$ Nadia G Kandile, (iD) 4

David RK Harding, ${ }^{5}$ Mohamed M

Ghoneim, (D) ${ }^{6}$ Waleed Zeiada, (iD) 7,8

Jayalakshmi Jagal, (iD ${ }^{2}$ Ahmed

Aboelnaga, ${ }^{9}$ Mohamed Haider (D) $2,10,11$

'Department of Oral and Craniofacial Health Sciences, College of Dental Medicine, University of Sharjah, Sharjah 27272, United Arab Emirates; ${ }^{2}$ Research Institute of Medical and Health Sciences, University of Sharjah, Sharjah 27272, United Arab Emirates;

${ }^{3}$ Department of Oral and Maxillofacial Surgery, Faculty of Dentistry, Suez Canal University, Ismaillia 4I522, Egypt; ${ }^{4}$ Department of Chemistry, Faculty of Women, Ain Shams University, Heliopolis, Cairo I I757, Egypt; ${ }^{5}$ School of Fundamental Sciences, Massey University, Palmerston North 4442, New

Zealand; ${ }^{6}$ Department of Oral and Maxillofacial Surgery, Faculty of Dentistry, Sinai University, Arish 455I I, Egypt; ${ }^{7}$ Department of Civil and Environmental Engineering, College of Engineering, University of Sharjah, Sharjah 27272, United Arab Emirates; ${ }^{8}$ Public Works Engineering Department, College of Engineering, Mansoura University, Mansoura 355 16, Egypt; ${ }^{9}$ Department of Surgery, Faculty of Medicine, Suez Canal University, Ismaillia 41522, Egypt; ${ }^{10}$ Department of Pharmaceutics and Pharmaceutical Technology, College of Pharmacy, University of Sharjah, Sharjah 27272, United Arab Emirates; "'Department of Pharmaceutics and Industrial Pharmacy, Faculty of Pharmacy, Cairo University, Cairo 71526, Egypt

Correspondence: Wael Talaat Oral and Maxillofacial Surgery, College of Dental Medicine, University of Sharjah,

Sharjah, United Arab Emirates

Tel +97। 65057605

Fax +97। 65057606

Email wtaha@sharjah.ac.ae
Purpose: Several scaffolds and cell sources are being investigated for cartilage regeneration. The aim of the study was to prepare nanocellulose-based thermosensitive injectable hydrogel scaffolds and assess their potential as 3D scaffolds allowing the chondrogenic differentiation of embedded human dental pulp stem and progenitor cells (hDPSCs).

Materials and Methods: The hydrogel-forming solutions were prepared by adding $\beta$ glycerophosphate (GP) to chitosan (CS) at different ratios. Nanocellulose (NC) suspension was produced from hemp hurd then added dropwise to the CS/GP mixture. In vitro characterization of the prepared hydrogels involved optimizing gelation and degradation time, massswelling ratio, and rheological properties. The hydrogel with optimal characteristics, NC-CS /GP-21, was selected for further investigation including assessment of biocompatibility. The chondrogenesis ability of hDPSCs embedded in NC-CS/GP-21 hydrogel was investigated in vitro and compared to that of bone marrow-derived mesenchymal stem cells (BMSCs), then was confirmed in vivo in 12 adult Sprague Dawley rats.

Results: The selected hydrogel showed stability in culture media, had a gelation time of 2.8 minutes, showed a highly porous microstructure by scanning electron microscope, and was morphologically intact in vivo for 14 days after injection. Histological and immunohistochemical analyses and real-time PCR confirmed the chondrogenesis ability of hDPSCs embedded in NC-CS/GP-21 hydrogel.

Conclusion: Our results suggest that nanocellulose-chitosan thermosensitive hydrogel is a biocompatible, injectable, mechanically stable and slowly degradable scaffold. hDPSCs embedded in NC-CS/GP-21 hydrogel is a promising, minimally invasive, stem cell-based strategy for cartilage regeneration.

Keywords: tissue regeneration, cartilage, scaffolds, stem cells, nanocellulose, chitosan, hydrogel

\section{Introduction}

Trauma or arthritic changes in the temporomandibular joint (TMJ) may lead to advanced forms of temporomandibular disorders (TMD), leaving patients with pain and disabilities that can negatively affect their quality of life. The treatment of the advanced stages of arthritis is challenging due to the limited blood supply of the TMJ, its inadequate capability for self-repair and the complexity associated with regenerating the osteochondral interface. Several scaffolds and cell sources are 
currently being investigated for the possibility of tissue regeneration of the TMJ. It is well known that autogenic cells are the ideal cell source for tissue regeneration. ${ }^{1}$

Although chondrocytes have been identified as a potential cell source for cartilage repair upon using the autologous transplantation techniques, several shortcomings have been reported which might limit their use such as their instability in monolayer culture, the donor site morbidity, insufficient cell number and limited capability for intrinsic repair. ${ }^{2}$ For these reasons, progenitor and stem cells have gained publicity for condylar cartilage engineering. Human umbilical cord mesenchymal stromal cells (hUCMSCs) are an alternative cell source for cartilage tissue engineering as they divide faster and produce more matrix when compared to condylar cartilage cells in vitro. ${ }^{3}$ On comparing hUCMSCs to bone marrow-derived mesenchymal stem cells (BMSCs) which are considered the standard stem cell source, the later produced more intense collagen type II staining, while the former produced more type I collagen and aggrecan in a $3 \mathrm{D}$ matrix. ${ }^{4}$ Adipose-derived stem cells also show characteristics of multipotent adult stem cells and have shown the ability to synthesize cartilage-specific matrix proteins, thus are regarded as a promising cell source for cartilage regeneration as well. ${ }^{5}$ However, the harvesting of all the previous types of stem cells requires invasive methods. Human dental pulp stem cells are neural crest-derived stem cells, which are obtained from the pulp of human teeth, intermingled with progenitor cells. hDPSCs are obtained noninvasively from extracted teeth that are often extracted for other reasons, and thus avoiding several ethical issues. hDPSCs have been reported to have high self-renewal capacity and immunomodulatory capability and are considered a potential cell source for joint cartilage tissue regeneration if delivered in a suitable scaffold. ${ }^{6}$

The presence of a scaffold at the defect area is critical to the process of cartilage regeneration, as it provides mechanical support to the cells and regenerated tissues. Hydrogelbased scaffolds have gained popularity because of their resemblance to the natural cartilage surroundings due to their high water content. The main advantage of a hydrogel scaffold is the possibility of being injected into the defect area, which avoids the need for any invasive surgery. ${ }^{7,8} \mathrm{NC}$ is a natural material with unique characteristics. These unique features include lack of toxicity, biocompatibility, biodegradability, superior rheological properties and mechanical reinforcement. Thus, nanocellulose qualifies to be considered as an optimum material for tissue engineering applications. ${ }^{9}$
$\mathrm{CS}$ is a natural biodegradable linear aminopolysaccharide derived from crustacean shells and widely used in drug delivery and tissue engineering. ${ }^{10,11} \mathrm{GP}$ is a natural body component used as a source of phosphate as well as in the treatment of phosphate metabolism disorders. ${ }^{12}$ Mixing CS and GP in aqueous media results in stimulusresponsive in situ forming gels which are produced due to a combination of $\mathrm{pH}$ - and temperature-dependent interactions. ${ }^{13}$ At temperatures below the critical solution temperature (CST) of CS, the addition of GP neutralizes the amino group on the polymer chains lowering the electrostatic repulsion between adjacent chains and forming $\mathrm{pH}$ induced gel. However, the hydroxyl groups on GP molecules attached to protonated amine groups $\left(-\mathrm{NH}_{3}{ }^{+}\right)$due to electrostatic attraction increase stability and hydrophilicity of the CS chains and maintain their solubility in aqueous media. Further increase in temperature above CST results in dehydration of the CS chains and reduction of their charge density as well as their attraction to GP. Those changes lead to an increase in interchain hydrophobic interactions and hydrogen-bonding and formation of hydrogels. ${ }^{14,15}$ This can be adjusted to occur at body temperature and at reasonable time frames through modifying the respective proportions of the ingredients. ${ }^{16}$ This hydrogel scaffold offers a biocompatible and biodegradable platform for various biomedical applications in controlled drug delivery and tissue engineering. ${ }^{17,18}$

The aim of the present study was to prepare nanocellulose-based thermosensitive injectable hydrogel scaffolds, determine their physical properties and assess their potential as 3D scaffolds that allow the chondrogenic differentiation of embedded hDPSCs, and compare it to the chondrogenic differentiation of BMSCs.

\section{Materials and Methods}

\section{Establishment of hDPSC and BMSC Cell}

\section{Lines}

Two stem cell sources were used in this study, namely hDPSCs obtained from primary culture and established $B M S C$ cell line. All experiments were done observing the national guidelines for working with human materials. The investigations were carried out following the rules of the Declaration of Helsinki of 1975, revised in 2013. The Research Ethics Committee at the University of Sharjah approved the procedure and the experimental protocol (REC/16/04/30). The isolation of hDPSCs involved the collection of non-carious impacted third molar teeth following extraction from young adults (20-23 years of age). All 
patients were informed of the aim of the study, and they signed a formal written consent before participation. Each extracted molar was cleaned and immediately immersed in minimum essential medium ( $\alpha$-MEM) with $0.5 \mathrm{mg} / \mathrm{mL}$ of gentamicin and $3 \mathrm{mg} / \mathrm{mL}$ of amphotericin B (Gibco BRL, Life Technologies B.V. Breda, The Netherlands). A cut was made around the cementum-enamel junction using a highspeed bur to expose the pulp chamber, and then the pulp was extracted. The coronary pulp was then ground and digested in a solution of $3 \mathrm{mg} / \mathrm{mL}$ collagenase/dispase (Roche, Basel, Switzerland) for 1 hour at $37^{\circ} \mathrm{C}$. Single-cell suspensions were obtained by passing the cells through a 70-mm Falcon Cell Strainer (Fisher Scientific, MA, USA). The released hDPSCs were seeded into 12-well plates with $\alpha$-MEM supplemented with FBS, $100 \mu \mathrm{g} / \mathrm{mL}$ L-ascorbic acid 2-phosphate (Wako Pure Chemicals, Osaka, Japan) $2 \mu \mathrm{g} / \mathrm{mL}$ L-glutamine, 100 units $/ \mathrm{mL}$ penicillin, $100 \mu \mathrm{g} / \mathrm{mL}$ streptomycin (Biofluids, Rockville, MD, USA), and then incubated at $37^{\circ} \mathrm{C}$ in $5 \% \mathrm{CO}_{2}$.

The established BMSCs cell line was obtained from Lonza (Walkersville, MD, USA). BMSCs were cultured in mesenchymal stem cell basal medium supplemented with mesenchymal cell growth supplement (Cambrex Bio Science, Verviers, Belgium), L-glutamine (Gibco BRL, Life Technologies B.V. Breda, The Netherlands), and antibiotics (penicillin/streptomycin; Gibco BRL, Life Technologies B.V. Breda, The Netherlands), and incubated at $37^{\circ} \mathrm{C}$ in a $5 \% \mathrm{CO}_{2}$ atmosphere. For all experiments, equivalent third passages of both cell types were used.

To examine phenotype, both cell types were analyzed by flow cytometry using commonly reported cell-surface markers. For each cell type, single-cell suspension at a concentration of $1 \times 10^{6} / 100 \mu \mathrm{L}$ in $1 \times$ phosphate buffer saline (PBS) (pH 7.4) was obtained and stained with CD44, CD90, CD106 positive markers and with CD45 and $\mathrm{CD} 11 \mathrm{~b}$ negative markers. Flow cytometry was done using BD FACSAria III sorter (BD Biosciences, CA, USA).

\section{Nanocellulose-Chitosan Hydrogel Preparation}

Nanocellulose was produced from hemp hurd. An amount of $5 \mathrm{~g}$ of hemp hurd was dewaxed by stirring in acetone/ water 9:1 (180 mL acetone: $\left.20 \mathrm{~mL} \mathrm{H}_{2} \mathrm{O}\right)$ for 24 hours. The mixture was then vacuum filtered and washed 4 times with $500 \mathrm{~mL}$ of reverse osmosis (RO) water. The fibers were stirred in $200 \mathrm{~mL} \mathrm{HCl}(\mathrm{pH} \mathrm{4.5)}$ with $3.5 \mathrm{~g}$ sodium chlorite $\left(\mathrm{NaClO}_{2}\right)$ for 5 cycles of 1.5 hours each. The fibers were then washed, then treated in water in a high-speed blender, then stored at $4^{\circ} \mathrm{C}$. In 1 litre of water, the blended fibres were treated with $0.5 \mathrm{~g}$ sodium bromide $(\mathrm{NaBr}), 0.08 \mathrm{~g}$ of TEMPO (2,2,6,6-tetra-methylpiperidine-1-oxyl radical) and $132.5 \mathrm{~mL}$ of sodium hypochlorite $(\mathrm{NaClO})$. The mixture was stirred at room temperature and the $\mathrm{pH}$ was kept at or above $\mathrm{pH} 10$ with $0.5 \mathrm{M}$ sodium hydroxide $(\mathrm{NaOH})$. The product was then filtered and washed then freezedried. CS (medium molecular weight, $70-85 \%$ deacetylation, Sigma Aldrich, St. Louis, MO, USA) was dissolved in $0.1 \mathrm{M}$ reagent grade acetic acid (Merck, Darmstadt, Germany) at room temperature and the resulting solution was then sterilized by autoclaving at $121^{\circ} \mathrm{C}$. A $50 \%(\mathrm{w} / \mathrm{v})$ GP (glycerol-2-phosphate salt hydrate, Sigma Aldrich, St. Louis, MO, USA) aqueous solution was prepared using distilled water, sterilized by filtration using Millex syringe driven 0.22-mm filter units (Millipore, MA, USA), and kept at $4^{\circ} \mathrm{C}$. Both solutions were chilled on ice under aseptic conditions and continuous stirring for 10 minutes before mixing. The hydrogel-forming solutions were prepared by adding GP aqueous solutions to the CS solution in acetic acid dropwise at different ratios then stored at $4^{\circ} \mathrm{C}$ for further characterization to prevent premature gelation. Cellulose nanofibers were dispersed in water at $3 \%$ $\mathrm{w} / \mathrm{v}$ using a magnet stirrer at medium speed for $30 \mathrm{~min}-$ utes. The resulting nanocellulose suspension was then added dropwise to the CS/GP mixture in a cold beaker and the resulting mixtures were stored at $4^{\circ} \mathrm{C}$ for further use (Table 1).

\section{In vitro Characterization of the Prepared Hydrogels}

The stability of the hydrogel scaffolds in culture media was determined by incubation of $1 \mathrm{~mL}$ of the prepared solution for 1 hour at $37^{\circ} \mathrm{C}$ to allow complete gelation. The weight of formed hydrogel was recorded followed by addition of $2 \mathrm{~mL}$ Chondromax differentiation media (Sigma, St. Louis, MO, USA) and incubation at $37^{\circ} \mathrm{C}$

Table I The Composition of Different Hydrogel Formulae

\begin{tabular}{|l|l|l|l|}
\hline \multirow{2}{*}{ Formula } & \multicolumn{2}{|l|}{ Ratio $\mathbf{w} / \mathbf{w}$} & NC \\
\cline { 2 - 3 } & CS & GP & \\
\hline CS/GP-II & 1 & 25 & - \\
CS/GP-2I & 2 & 25 & - \\
CS/GP-3I & 3 & 25 & - \\
NC-CS/GP-2I & 2 & 25 & 4 \\
\hline
\end{tabular}


under $5 \% \mathrm{CO}_{2}$. Changes in the weight of the hydrogels were measured over 14 days and normalized to their initial values before degradation. All the experiments were done in triplicate under sterile condition to prevent bacterial and fungal contamination. The time required for gel formation was determined using the tube inversion method. ${ }^{19}$ Briefly, glass vials containing $2 \mathrm{~mL}$ of the hydrogel were incubated in a water bath at $37^{\circ} \mathrm{C}$ and the flowability of the solutions was examined every 20 seconds by inverting the vials. The time required to form a gel that did not flow within 5 seconds following vial inversion was recorded. All measurements were done in triplicate, and the average gelation time was calculated for each sample.

In order to determine the mass-swelling ratio (Qm) equal volumes of hydrogel-forming solutions were incubated at $37^{\circ} \mathrm{C}$ for 24 hours. The formed gels were gently blotted dry to remove excess solvent, and then weighed to obtain the wet weight $(\mathrm{Mw})$. The hydrogels were then transferred to a $-80^{\circ} \mathrm{C}$ freezer for 8 hours then freeze dried using lyophilizer (Vir Tis Bench Top Pro, SP Scientific, PA, USA) for 24 hours at $-50^{\circ} \mathrm{C}$ and a pressure of $7 \times 10^{-2}$ mbar and their dry weight $(M d)$ was determined. The mass-swelling ratio (Qm) was determined by calculating the ratio of wet weight to dry weight (Mw/Md). The measurements were performed in triplicate and the mass-swelling ratio for each gel preparation was recorded.

\section{Scanning Electron Microscope (SEM)}

The shape and surface morphology of the hydrogel in presence and absence of NC were observed by field emission scanning electron microscope (JSM-633OF; JEOL, Tokyo, Japan). The prepared hydrogel was kept at $-80^{\circ} \mathrm{C}$ for 6 hours followed by lyophilization as described above. The dry samples were fixed with conductive tape on a metal stub, sputter-coated with a Gold-Palladium (8020\%) target using Mini Sputter Coater (SC7620, Quorum Technologies, East Sussex, UK) and examined at a $15 \mathrm{kV}$ accelerating voltage with a working distance of $17 \mathrm{~mm}$.

\section{Rheological Measurements}

The rheological properties of hydrogel formulae containing CS to GP at 2:25 (w/w) ratio with and without $\mathrm{NC}$ were measured using Brookfield rotational viscometer (DV3T) (AMETEK Brookfield, MA, USA). Spindle number (SC-27) was used for all tested gel specimens. Following the manufacturer guidelines, the size of the tested specimen was calculated to be $15 \mathrm{~mL}$ using the aforementioned spindle size and the standard viscometer tube (HT-2). The change in viscosity behavior of the hydrogel over a temperature range of $25^{\circ} \mathrm{C}$ to $37^{\circ} \mathrm{C}$ every $1{ }^{\circ} \mathrm{C}$ using a constant shear rate of $6.8 /$ second $(20$ RPM) was determined. The effect of shear rate on the viscosity of the prepared injectable formula was also measured over a shear rate range of $2 /$ second to $25 /$ second at a fixed temperature of $25^{\circ} \mathrm{C}$.

\section{Cell Viability}

Cultured BMSCs and hDPSCs were washed with PBS and then trypsinized using $0.5 \%$ trypsin EDTA solution (Sigma, St. Louis, MO, USA) then centrifuged at $1500 \mathrm{rpm}$ for 5 minutes. The supernatant was removed, and cells were suspended in complete medium and $1 \times 10^{6}$ cells in $100 \mu \mathrm{L}$ medium were acquired. The cells were then mixed with NC-CS/GP-21 hydrogel then $50 \mu \mathrm{L}$ of the mixture were added to a 96 -well plate $\left(2 \times 10^{4}\right.$ cells/well $)$. For cells outside the hydrogel and negative control group, $50 \mu \mathrm{L}$ of each were added directly to 96 -well plates. All plates were then incubated at $37^{\circ} \mathrm{C}$ in $5 \% \mathrm{CO}_{2}$. After 2 hours of incubation, $100 \mu \mathrm{L}$ of growth medium was added into the wells, and then cells were incubated at $37^{\circ} \mathrm{C}$ in $5 \%$ $\mathrm{CO}_{2}$ for 21 days. Cell viability was detected using Cell Proliferation Kit II (Sigma, St. Louis, MO, USA) according to the manufacturer's instructions. Absorbance was measured using a spectrophotometer at $490 \mathrm{~nm}$ with a reference wavelength at $650 \mathrm{~nm}$. Experiments were carried out in four replicates and repeated twice before calculating the average viability.

\section{Chondrogenic Differentiation Induction}

BMSCs and hDPSCs were detached from culture plates using 0.5\% trypsin EDTA solution (Sigma, St. Louis, MO, USA) and centrifuged at $1500 \mathrm{rpm}$ for 5 minutes. For each cell type, $2 \times 10^{6}$ cells $/ \mathrm{mL}$ were cultured in 6 well plate using human mesenchymal stem cell medium (Lonza, Walkersville, MD, USA) for 12 hours. The culture media was then replaced with Chondromax differentiation media (Sigma, St. Louis, MO, USA) for chondrogenic differentiation group, and with standard complete medium for control group. The cells were mixed with NC-CS/GP-21 hydrogel and $400 \mu \mathrm{L}$ of the mixture were placed in 24 well, 0.4 um pore size, transwell inserts and were then incubated at $37^{\circ} \mathrm{C}$ in $5 \% \mathrm{CO}_{2}$ for 2 hours. Five hundred microlitres of Chondromax differentiation medium was added for the chondrogenic differentiation group and $500 \mu \mathrm{L}$ of standard complete medium was added for the 
control group and the cells with hydrogels were incubated at $37^{\circ} \mathrm{C}$ in $5 \% \mathrm{CO}_{2}$ for 21 days. The medium for all groups was changed every 3 days during the culture period.

\section{In vivo Implantation}

Animal ethics approval was obtained from Suez Canal University Animal Ethics Committee with reference number 4187. All experiments were done following the ethical guidelines by the International Council for Laboratory Animal Science (ICLAS). Twelve adult male Sprague Dawley rats with an average weight of $200 \mathrm{~g}$ which were age-matched were used for the in vivo study. Sterilization of the injected hydrogels was obtained by autoclaving the CS solutions at $121^{\circ} \mathrm{C}$ for 10 minutes, filtration of NC and GP solutions, and sterile preparations of the hydrogel. General anesthesia was achieved using intramuscular injections of ketamine hydrochloride $(50 \mathrm{mg} / \mathrm{kg})$ and xylazine $(5 \mathrm{mg} / \mathrm{kg})$, followed by maintained inhalation of isofluorane. The animals' coat on the back was shaved and cleaned with povidone-iodine. Dorsal-subcutaneous injections were done using hypodermic syringes with 22-gauge needles, where each injection was $0.2 \mathrm{~mL}$ in volume (Figure 1A). The NCCS/GP-21 hydrogel with embedded hDPSCs, prepared as described in the chondrogenic differentiation group, was injected using the dorsal-subcutaneous approach in 9 rats. Approximately $4.0 \times 10^{6}$ cells were mixed with $2.0 \mathrm{~mL}$ of the hydrogel to be used for the in vivo implantation. Three rats were injected with hydrogel with no embedded cells to act as controls. Animals in both groups were housed in standard cages and fed with fixed formulation diet for laboratory rats fortified with vitamins and minerals. They were carefully monitored for daily activity and the injection
A

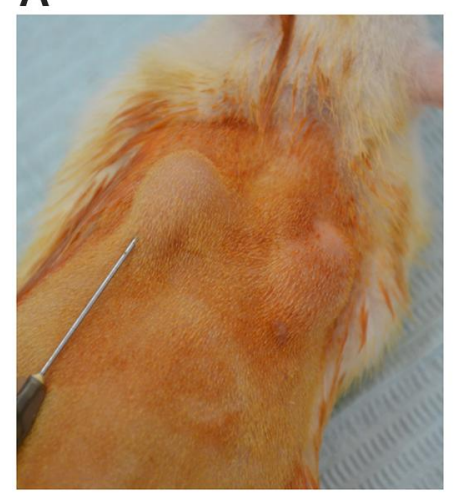

B

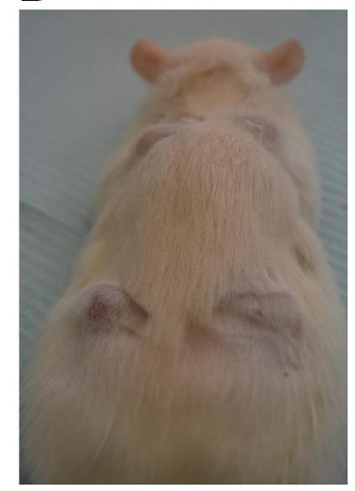

Figure I (A) Dorsal-subcutaneous injection of $0.2 \mathrm{~mL}$ of hDPSCs-laden NC-CS /GP-2I hydrogel. (B) Gel-implants with original bean-like shapes that remained quite morphologically intact for 14 days. sites were inspected for signs of wound infection. Euthanasia was performed using an intravenous overdose of pentobarbital. The control animals were sacrificed after 21 days, whereas the animals injected with the hDPSCsembedded hydrogel constructs were sacrificed at 7, 14 and 21 days. Blocks of tissue comprising skin and subcutaneous tissue, $10 \mathrm{~mm}$ by $10 \mathrm{~mm}$ in size, around the injection sites were excised using a surgical scalpel blade. Standard fixation techniques as described above were employed and all constructs were cut into $3 \mu \mathrm{m}$ sections for histological and immunohistochemistry analysis.

\section{Histochemistry and Immunohistochemistry}

The chondrogenesis ability of hDPSCs embedded in NCCS/GP-21 hydrogel was investigated in vitro and compared to that of BMSCs, then was confirmed in vivo. Approximately, $2 \times 10^{6}$ of hDPSCs, and equal quantity of BMSCs, were mixed with $4.0 \mathrm{~mL}$ of the hydrogel and $400 \mu \mathrm{L}$ of the mixture were placed in a 24 -well plate. The hydrogel constructs with embedded BMSCs and hDPSCs from the chondrogenic differentiation group and control group, as well as the tissue samples obtained at 7, 14 and 21 days were fixed overnight in PBS buffered 4\% paraformaldehyde ( $\mathrm{pH}$ 7.4), then dehydrated through a series of ethanol infiltrated with xylene and embedded in paraffin. All constructs were cut into $3 \mu \mathrm{m}$ sections. The slides were baked on a hot plate at $62^{\circ} \mathrm{C}$ for 30 minutes, followed by deparaffinisation and rehydration, then samples were stained with haematoxylin and eosin (H\&E) to evaluate cell morphology.

For immunohistochemical analyses, anti-collagen II antibody (PA5-99159) (Thermo Fisher Scientific, MA, USA) was used to examine the expression of collagen II in vitro in the hydrogel constructs with embedded BMSCs and hDPSCs from the chondrogenic differentiation group and control group, and in tissue samples obtained at 7, 14 and 21 days following the in vivo injections. The $5-\mu \mathrm{m}$ paraffin embedded sections were deparaffinised then treated by $0.3 \% \mathrm{H}_{2} \mathrm{O}_{2}$ for 20 minutes then incubated with 100 $\mu \mathrm{L}$ of 1:100 diluted anti-collagen II antibody overnight at $4^{\circ} \mathrm{C}$. The sections were then washed by PBS and incubated with Dako EnVision System- HRP (Abcam, Cambridge, UK) for 20 minutes then incubated with diaminobenzidine (DAB) for 15 minutes then washed by PBS and dehydrated for microscopic examination. Six non-overlapping fields were randomly selected per tissue section of each sample for the semi-quantitative analysis of immunohistochemical expression levels. Analyzed data were obtained 
using the Leica application module for histological analysis microscopic imaging system at a magnification of $400 \mathrm{x}$ (Leica Microsystems, Wetzlar, Germany).

\section{RNA Isolation, cDNA Synthesis and Real-Time PCR}

BMSCs and hDPSCs in NC-CS/GP-21 hydrogel $\left(2 \times 10^{6}\right.$ cells $/ 4.0 \mathrm{~mL}$ ) were incubated at $37^{\circ} \mathrm{C}$ in $5 \% \mathrm{CO}_{2}$ for 21 days after adding $500 \mu \mathrm{L}$ of Chondromax differentiation medium for the differentiation group and $500 \mu \mathrm{L}$ of standard complete medium for the control group. The medium of all groups was changed every 3 days during the culture period. After 21 days, the hydrogels were frozen in liquid nitrogen and minced using a mortar pestle. The total RNA was extracted using GenElute Universal Total RNA Purification Kit (Sigma, St. Louis, MO, USA) following the manufacturer's instructions. Then, $500 \mathrm{ng}$ of total RNA was reverse transcribed into first-strand cDNA using the High-Capacity cDNA Reverse Transcription Kit (Fisher Scientific, MA, USA) following the manufacturer's instructions. Quantitative real-time PCR was then performed using the TaqMan Gene Expression Master Mix (Fisher Scientific, MA, USA). The sequences of probes used to assess the expression of aggrecan, type $\mathrm{X}$ collagen and collagen II were the TaqMan gene expression assay, cat no: Hs01048719_g1, the TaqMan gene expression assay, cat no:Hs00166657_m1, and the TaqMan gene expression assay, cat no: Hs00264051_m1 (Thermo Fisher Scientific, MA, USA) respectively. All real-time PCR reactions were performed in triplicates and $\mathrm{Cq}$ values were averaged. $\Delta \mathrm{Cq}$ were calculated for the target genes (aggrecan, type $\mathrm{X}$ collagen and collagen II) with housekeeping gene glyceraldehyde-3-phosphate dehydrogenase. Relative gene expression $\left(2^{\wedge}-\Delta \Delta \mathrm{Cq}\right)$ was calculated for chondrogenic differentiated cells with non-differentiated cells as control.

\section{Statistical Analysis}

Data analysis was performed using the Statistical Package for Social Sciences (SPSS) version 16.0 (SPSS Inc., Chicago, IL, USA). All experiments were conducted at least three times. Data were expressed as mean \pm standard deviation (SD). Normality test for the quantitative analysis of immunohistochemistry showed the data were normally distributed. One-way ANOVA was used to analyze the quantitative immunohistochemistry results at different time points. Independent samples $t$-test was used to compare the means of independent groups. P-values of $<0.05$ were considered statistically significant.

\section{Results}

\section{Immunophenotypic Analyses of BMSCs and hDPSCs}

The released $h D P S C s$ isolated from extracted third molars and the established BMSC cell lines were expanded by culture. Flow cytometry analyses showed that both hDPSCs and BMSCs expressed CD44, CD90 and CD106 surface markers, and did not express CD11b and CD45 surface markers.

\section{Preparation and Characterization of Hydrogels}

At room temperature, CS/GP hydrogels with and without $\mathrm{NC}$ were colorless transparent liquids that underwent a sol-to-gel transition at physiological temperature $\left(37^{\circ} \mathrm{C}\right)$ where they formed turbid non-flowing hydrogels. The hydrogel degradation was measured in terms of percentage weight loss after incubation in culture media (Figure 2A). The hydrogels showed an increase in the weight loss as a function of time. The results showed that the degradation was affected by the composition of the hydrogel where CS/GP-11 scaffolds prepared using CS to GP at 1:25 w/w ratio lost more than $25 \%$ of their weight within 3 days and disintegrated into small fragments in the culture media. CS/GP-21 and CS/GP-31 with CS to GP w/w ratio of 2:25 and 3:25 respectively showed better stability in the culture media and kept the integrity up to 7 days before crumbling into small gel fragments. Accordingly, $\mathrm{NC}$ was added to mixtures containing CS to GP w/w ratio of 2:25 as they showed good stability and contained less CS hence expected to be more biocompatible. The addition of NC increased the stability of the hydrogels in culture media for more than 14 days.

Gelation onset and completion values were measured at $37^{\circ} \mathrm{C}$ for all hydrogels. The gelation time for $\mathrm{CS} / \mathrm{GP}$ scaffolds was found to be in the range of 1.8-5.5 minutes and was significantly affected by the ratio of CS to GP (Figure 2B). Increasing the concentration of CS resulted in faster gelation. The addition of $\mathrm{NC}$ to mixtures of $\mathrm{CS} / \mathrm{GP}$ at $2: 25 \mathrm{w} / \mathrm{w}$ ratio slightly decreased its gelation time to 2.8 minutes at $\mathrm{pH}$ 7.4. The results of hydrogel swelling in aqueous solution showed an increase in swelling upon increasing the $\mathrm{CS}$ to GP ratio (Figure $2 \mathrm{C}$ ). 


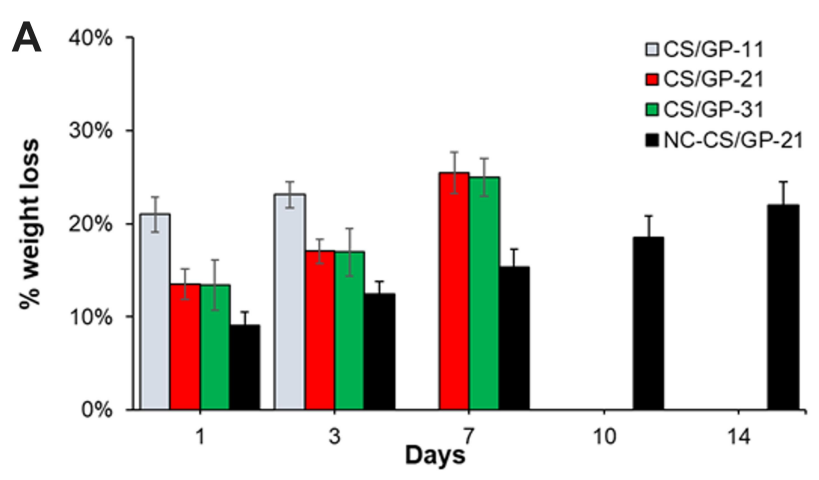

C
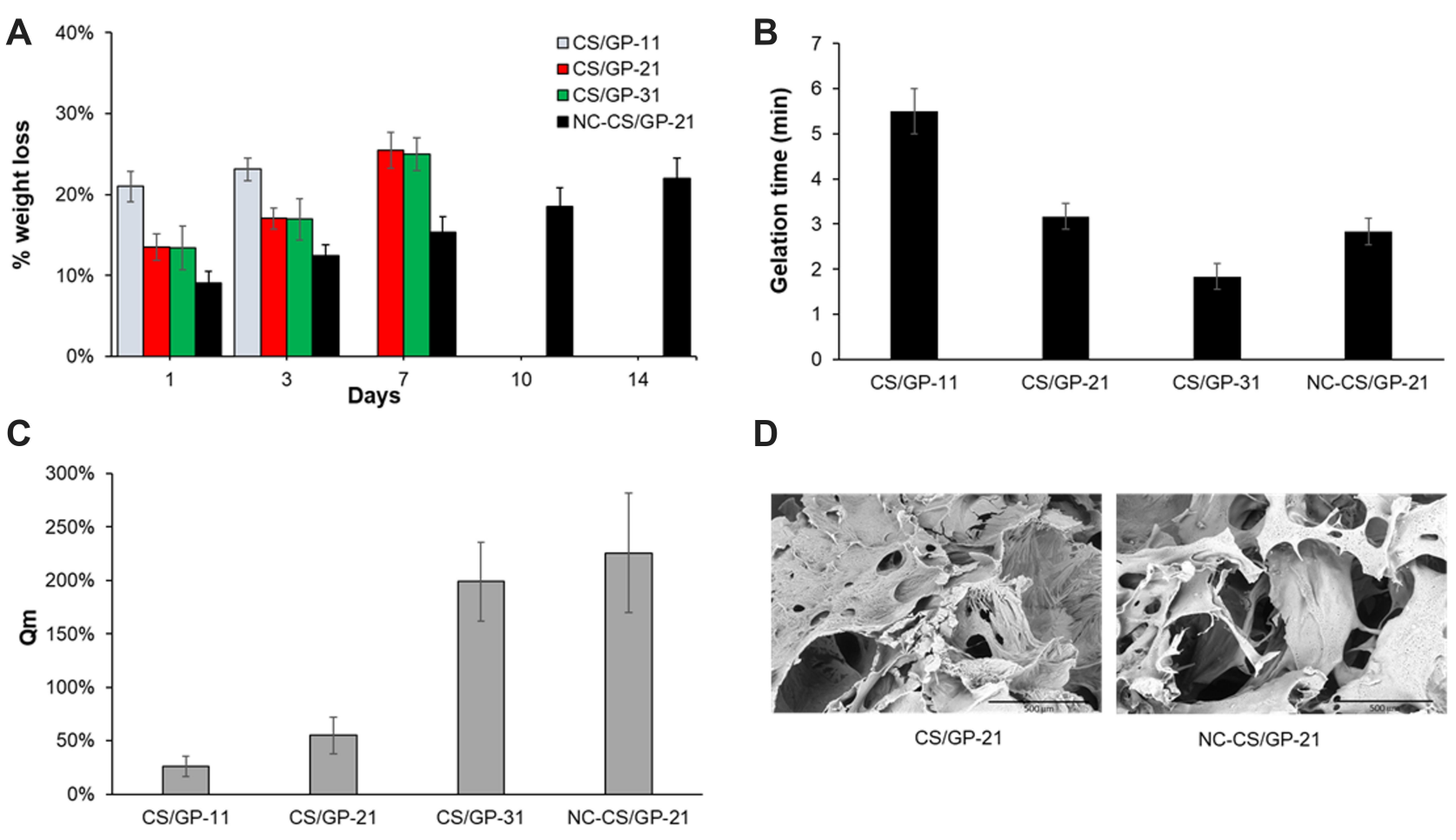

D

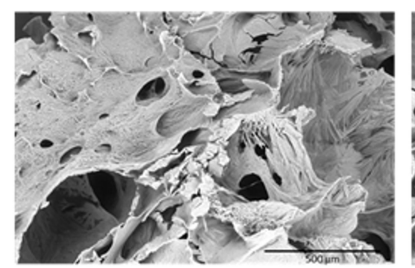

CS/GP-21

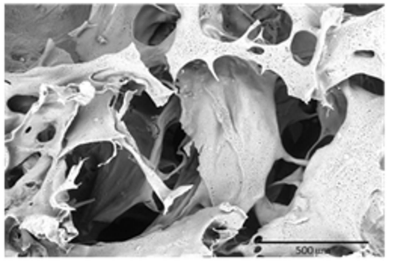

NC-CS/GP-21

Figure 2 Characterization of the hydrogel scaffolds. (A) Gel degradation after incubation in culture media at $37^{\circ} \mathrm{C}$ and $5 \% \mathrm{CO}$, Data points are mean $\pm \mathrm{SD}$ ( $\mathrm{n}=3$ ). $(\mathbf{B})$ Time required for gelation after incubation at $37^{\circ} \mathrm{C}$, Data points are mean $\pm S D(n=3)$. (C) Determination of $Q m$, Data points are mean $\pm S D(n=3)$. (D) SEM micrographs showing the porous structure of CS/GP-2I and NC-CS/GP-2I.

SEM was used to evaluate the pore architecture in the prepared hydrogel. The obtained micrographs for both CS/ GP and NC-CS/GP-21 hydrogel scaffolds showed a diversified, highly porous microstructure with pore size in the range of $100-400 \mu \mathrm{m}$. The structures of both scaffolds were also distinguished by their surface irregularities and a high degree of interconnectivity (Figure 2D).

\section{Rheological Measurements}

The determination of the rheological properties of the prepared injectable solutions showed that NC-CS/GP-21 had a higher baseline viscosity at $25^{\circ} \mathrm{C}$. The viscosity of CS/GP-21 and NC-CS/GP-21 decreased as the shear rate increased. The viscosity dropped dramatically at the beginning before starting to stabilize between $15 /$ second and 20 / second with almost no change between 20/second and 25/ second shear rates (Figure 3A). Both tested formulation specimens showed steady viscosity levels at temperatures below $31^{\circ} \mathrm{C}$ before showing a noticeable gradual increase in their viscosity (Figure 3B).

\section{Cell Viability}

The quantitative evaluation of the percentage of living cells in NC-CS/GP-21 hydrogel showed an average of 85 $\pm 6.5 \%$ viable BMSCs after 21 days, whereas the percentage of viable hDPSCs was $75 \pm 4.9 \%$. The difference between the mean values of the percentage of living hDPSCs and BMSCs was not significant $(P>0.05)$. Cells outside the hydrogel revealed $95 \pm 4.3 \%$ viability whereas the negative control showed $8 \pm 1.2 \%$ viability.

\section{In vivo Implantation}

The NC-CS/GP-21 hydrogel with embedded hDPSCs was easily injected using a dorsal-subcutaneous approach. All animals were healthy and active till the end of the experiment. The needle puncture wounds resulting from the injection of the hDPSCs-NC-CS/GP-21 construct healed within the first 24 hours following the procedure. Daily observation showed an acute inflamed skin at the implantation site during the first week. The inflammatory process resolved rapidly by the tenth post-implantation day. There were no signs of acute allergic reaction following the implantation. The subcutaneous implants acquired beanlike shapes and remained quite morphologically intact when surgically retrieved at 7 and 14 days and gradually decreased in size till 21 days (Figure 1B). There was no migration of the gel implants and the implanted sites were free from granulomatous tissues. 

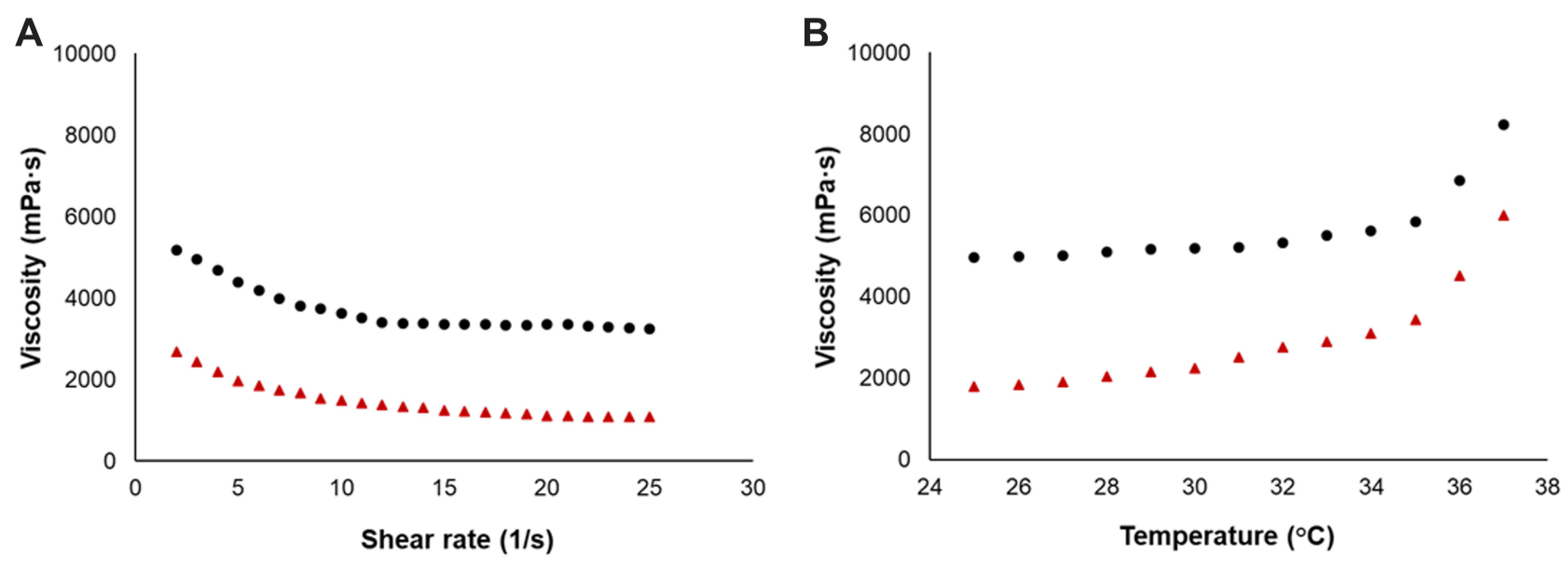

Figure 3 Viscosity behavior of $(\bullet)$ NC-CS/GP-2I and $(\mathbf{\Delta})$ CS/GP-2I hydrogels upon $(\mathbf{A})$ increasing the shear rate (at constant temperature $\left.25^{\circ} \mathrm{C}\right)$ and $(\mathbf{B})$ increasing the temperature (at shear rate of $6.8 / \mathrm{sec}$ ).

\section{Histological and Immunohistochemical Analyses of Chondrogenesis in Nanocellulose-Chitosan Hydrogel}

H\&E staining revealed that both types of cells in the chondrogenic differentiation group were rounded, separated by abundant extracellular matrix, and showed chondrocyte-like morphology. However, most cells in the control group showed a fibroblast-like morphology. Tissue samples at 7 days showed polymorphonuclear inflammatory cell infiltrates accompanied by significant fibroblastic activity and newly formed collagen fibers. At 14 days, there was a significant reduction in the inflammatory reaction with higher fibroblastic activity and more collagen fibers deposition. The formation of eosinophilic matrix resembling cartilage tissue was found accompanied by dilated and congested subcutaneous blood vessels. At 21 days, samples showed almost complete lysis of the injected biomaterial and replacement with granulation tissue with higher fibroblastic activity. More collagen fiber deposition was detected accompanied by dilated and congested subcutaneous blood vessels (Figure 4). For the in vitro studies, the chondrogenic differentiation of both types of cells was also confirmed by the strong staining for chondrocyte-specific protein; collagen II by immunohistochemistry, whereas the staining was much weaker in the control group. Tissue samples from the in vivo studies showed positive staining for collagen II, compared to weak staining for the control (Figure 5).

The semi-quantitative analysis of the immunohistochemical expression levels showed a highly significant increase at 7 days, 14 days and 21 days, respectively
$(P<0.001)$ (Table 2). The difference between the mean values of the immunohistochemical expression levels at 21 days compared to control was highly significant $(P<0.001)$.

\section{Real-Time PCR}

Real-time PCR was used to evaluate the expression of aggrecan, type $\mathrm{X}$ collagen and collagen II. Hydrogelembedded BMSCs and hDPSCs cultured in chondrogenic media for 3 weeks were investigated. Cells maintained in standard complete media were used as negative control. Quantitative analysis showed that the expression of aggrecan, type X collagen and collagen II was significantly higher in cells cultured in chondrogenic media when compared to control cells. The highest gene expression was detected on day 21. The difference between the gene expression for BMSCs and hDPSCs was not significant $(P>0.05)$ (Figure 6). The results for real-time PCR were consistent with the results obtained by the immunohistochemistry analysis.

\section{Discussion}

Tissue engineering furnishes new opportunities for the regeneration of damaged and degenerated TMJ cartilages and can be extremely valuable with the increasing incidence of TMD. Till the moment, no surgical approach has been able to replicate the biological and mechanical properties of the original cartilage. Because of the distinctive nature of the TMJ, and the uniqueness of the loading patterns inside that joint, the regeneration of the original damaged tissues would be the optimum solution for managing advanced forms of TMD. ${ }^{20,21}$ The choice of an 
A

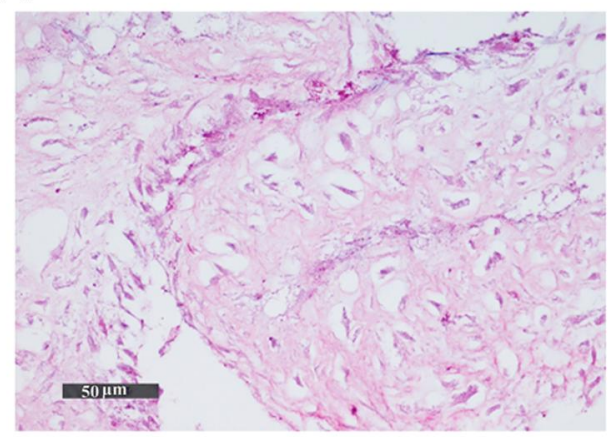

C

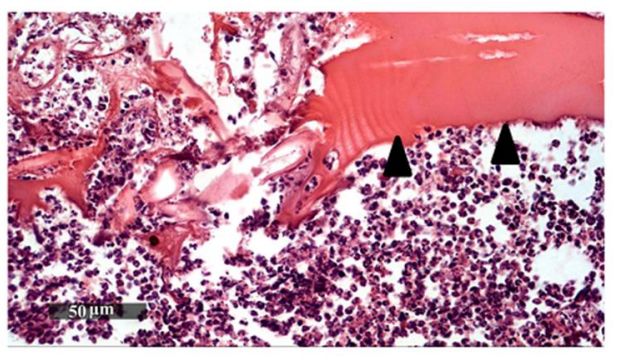

E

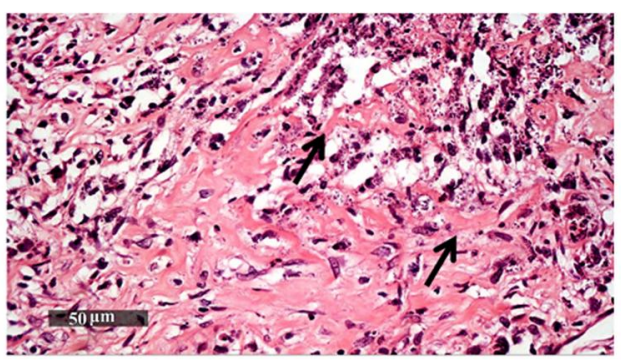

B

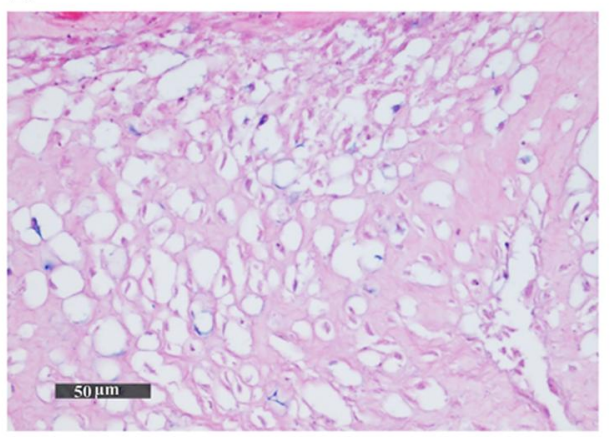

D

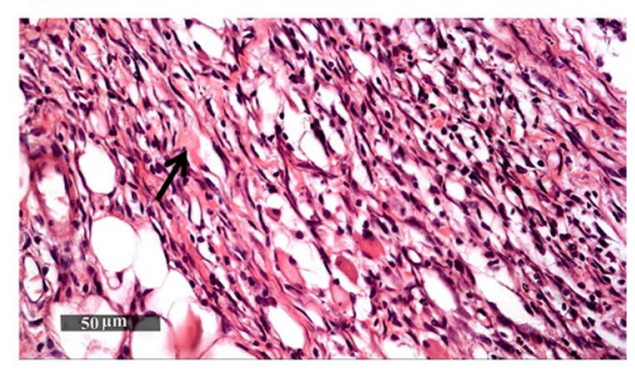

$F$

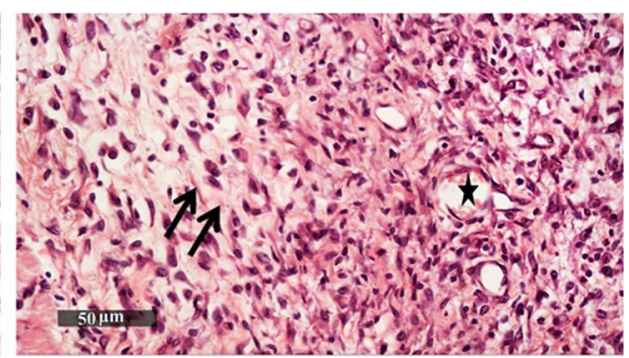

Figure $4 \mathrm{H \& E}$ staining showing the in vitro chondrogenic differentiation of BMSCs (A), and of hDPSCs (B) in the NC-CS/GP-2I hydrogel. H\&E staining for in vivo tissue samples obtained at 7 days showing subcutaneous eosinophilic-injected biomaterial (arrow head) surrounded by abundant polymorphonuclear inflammatory cells infiltrates (C), significant fibroblastic activity and newly formed collagen fibers (arrow) (D). At 14 days, there was a significant reduction in the inflammatory reaction with reduced mononuclear inflammatory cells infiltration with higher fibroblastic activity and more collagen fibers deposition (arrow) (E). At 2 I days, samples showed granulation tissue with higher fibroblastic activity. More collagen fiber deposition (arrow) was detected accompanied by dilated and congested subcutaneous blood vessels (star) (F).

optimal cell source and scaffold is of prime importance for the success of cartilage regeneration. Hydrogel-based scaffolds have recently gained popularity for cartilage engineering procedures due to their closeness to the natural cartilage medium. The high water content in a hydrogel makes it similar to the natural cartilage environment and allows the influx of solutes and nutrients into the cells, and the outflow of the waste products from the hydrogel. Moreover, hydrogel scaffolds encapsulate the cells maintaining their viability. The liquid nature of thermosensitive hydrogels, which change to gel state at body temperature, makes it possible for the hydrogel to be injected into the defective area, avoiding the need for invasive surgery and reducing patients' morbidity. Injectable hydrogels can reach deep tissue defects, adapt well to the margins, and completely fill the defect, even if it is irregular in shape, leading to neovascularization. ${ }^{22}$

Nanocellulose is the nanoscaled form of cellulose; the earliest polymer on earth. The exceptional physical, chemical and biological properties of nanocellulose allow its use in various biomedical applications. Among these biomedical applications are drug delivery, ${ }^{23,24}$ blood vessel replacement, $^{25}$ ligaments, meniscus and cartilage replacements, ${ }^{26,27}$ antimicrobial nanomaterial, ${ }^{28}$ and tissue repair, regeneration and healing. ${ }^{29,30}$ Nanocellulose provides an optimum environment for cell-based regeneration applications, attributed to its biocompatibility and mechanical properties, allowing for cell attachment and proliferation, $^{31}$ and its slow biodegradation which is a favorable property for use in tissue regeneration. ${ }^{32}$ The 
A

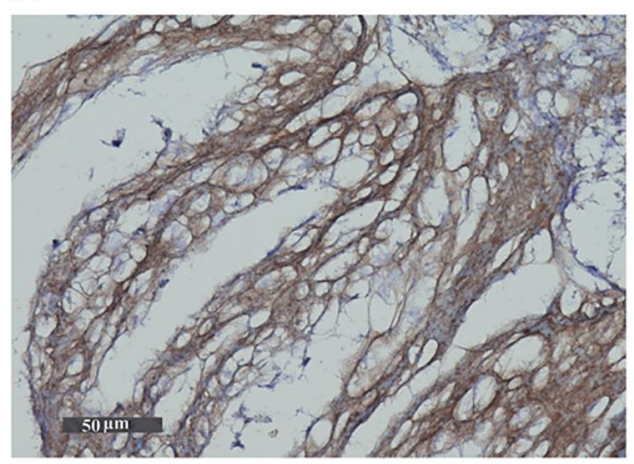

C

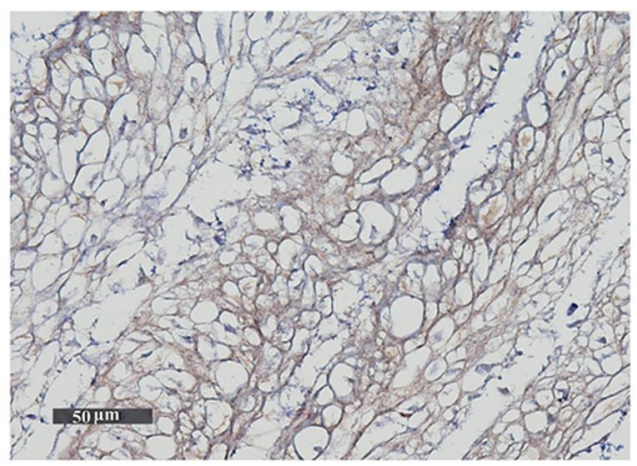

E

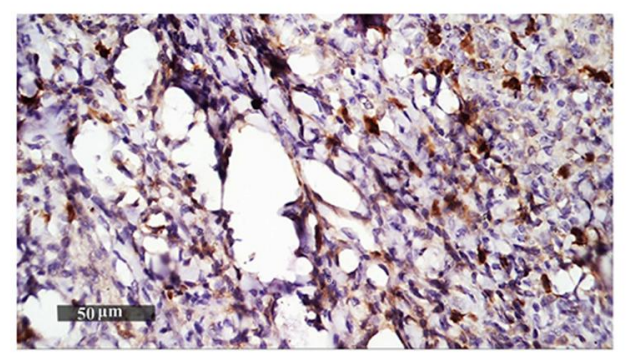

G

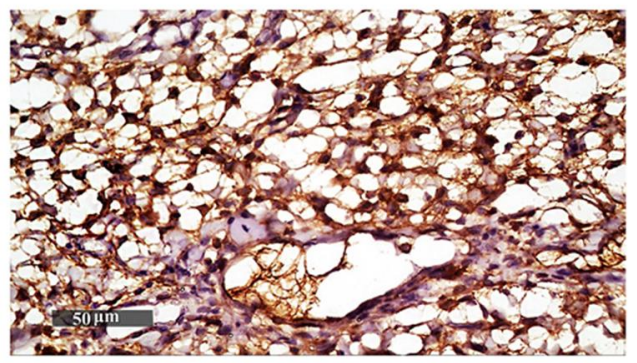

B

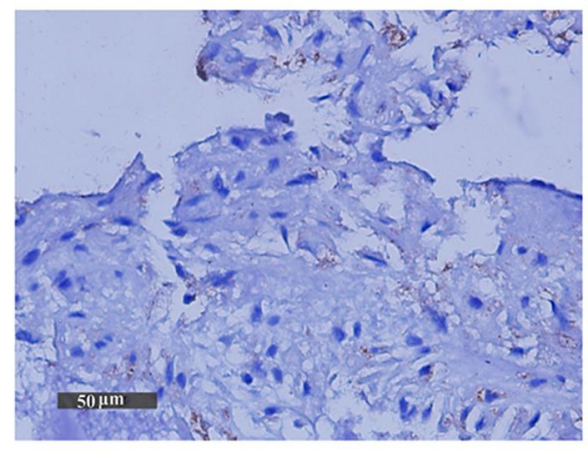

D

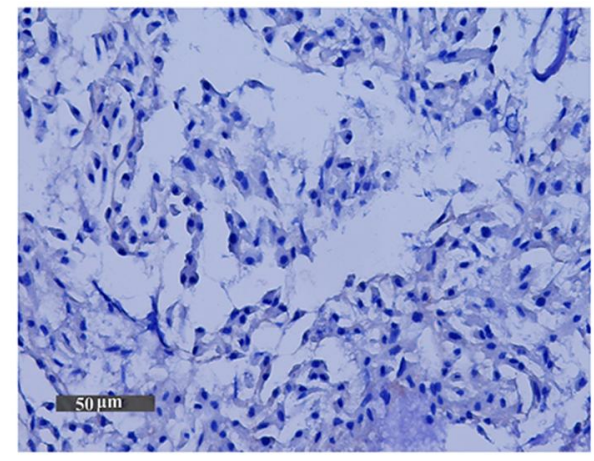

$\mathbf{F}$

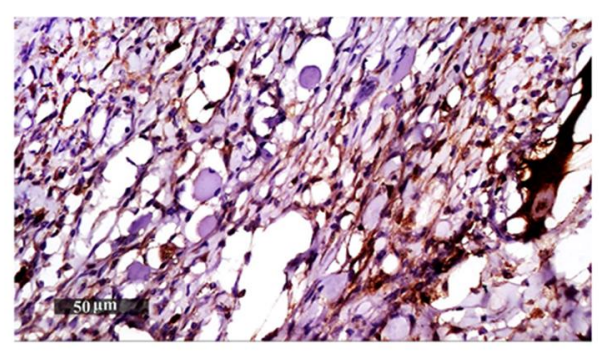

$\mathrm{H}$

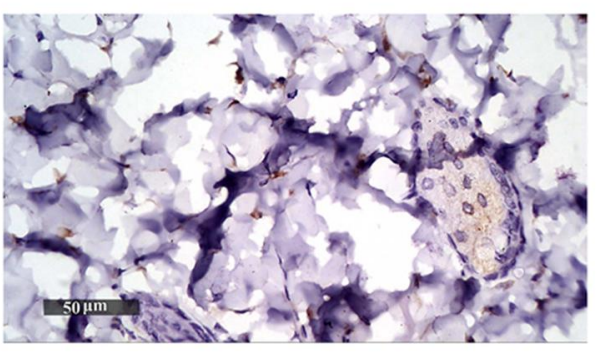

Figure 5 Immunohistochemical analysis of the in vitro expression of collagen II in the NC-CS/GP-2I hydrogel-embedded BMSCs and hDPSCs after 3 weeks of cultivation. The analysis of expression of collagen II with hDPSCs in chondrogenic medium (A), and in standard complete medium (control) (B), and the expression of collagen II with BMSCs in chondrogenic medium (C), and in standard complete medium (control) (D). Immunohistochemical analysis of the in vivo tissue samples showed positive staining for collagen II at 7 days $(\mathbf{E})$, at 14 days $(\mathbf{F})$, at 2 I days $(\mathbf{G})$, and weak staining for the control group $(\mathbf{H})$.

integrity of the thermosensitive hydrogel after injection in the desired site of action is essential to prevent infiltration of the cell load from the scaffold to neighboring tissues.
Application of CS/GP hydrogels can be limited by their low mechanical strength, fast degradation and loss of spatial support, ${ }^{33}$ whereas the combination of $\mathrm{NC}$ with 
Table 2 Semi-Quantitative Analysis of the Immunohistochemical Expression Levels for Tissue Samples

\begin{tabular}{|l|l|l|l|l|l|l|l|l|}
\hline & Number & Mean & Standard Deviation & Standard Error & \multicolumn{2}{|l|}{ 95\% Confidence Interval for Mean } & F & P value \\
\cline { 4 - 7 } & & & & & Lower Bound & Upper Bound & \\
\hline 7 days & 6 & 13.82 & 1.24 & 0.51 & 12.52 & 15.12 & 188.86 & $<0.00 I^{*}$ \\
14 days & 6 & 25.62 & 1.86 & 0.76 & 23.66 & 27.57 & \\
21 days & 6 & 29.78 & 1.24 & 0.50 & 28.49 & 31.08 & \\
\hline
\end{tabular}

Note: * Highly statistically significant.

CS has been attempted to improve the latter's biocompatibility, biodegradation and mechanical properties. ${ }^{34}$ In the present study, the CS/GP-21 and CS/GP-31 hydrogel formulas with CS to GP w/w ratio of 2:25 and 3:25 respectively showed better stability and slower degradation in the culture media and kept the integrity up to 7 days before crumbling into small gel fragments. The addition of NC to the CS/GP-21 formula increased the stability of the hydrogels in culture media for more than 14 days. The degradation of highly porous CS/GP hydrogels in aqueous solutions occurs by bulk-erosion process which occurs when the rate of water diffusion into the sample is much faster than the hydrolysis reaction. The slower degradation of hydrogels with higher CS to GP ratio, CS/GP-21 and $\mathrm{CS} / \mathrm{GP}-31$ is in correlation with a previous study that suggested that this may occur due to the increase in entanglement and physical cross-linking density in the hydrogel. ${ }^{35}$ Similarly, the significant increase in the

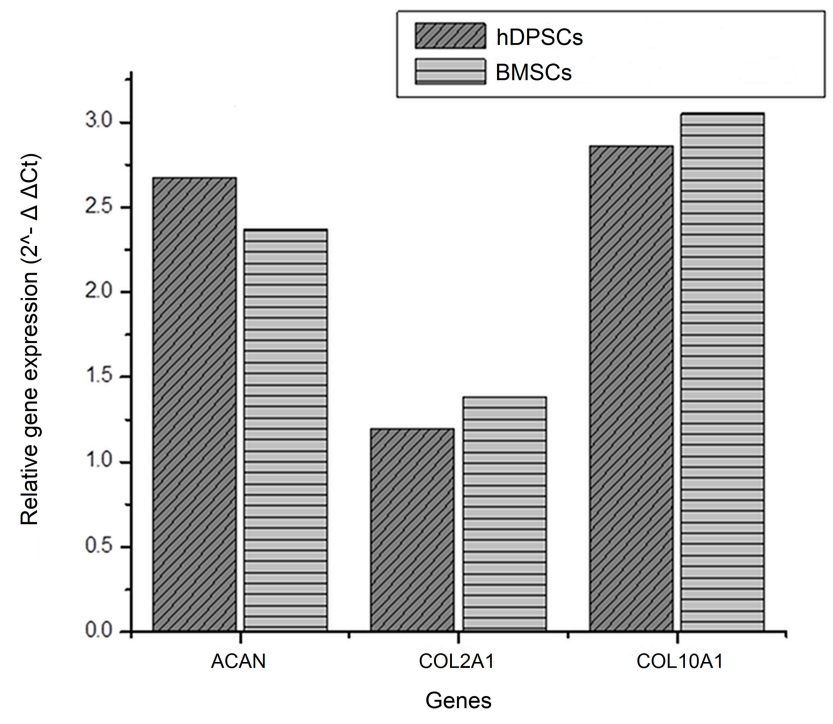

Figure 6 Relative gene expression of aggrecan (ACAN), collagen II (COL2AI), and type $X$ collagen (COLIOAI) by real-time PCR. Relative gene expression $\left(2^{\wedge}-\Delta \Delta \mathrm{Ct}\right)$ was calculated for chondrogenic-differentiated cells with non-differentiated cells as control. The values were demonstrated by three independent experiments at each time point, $\mathrm{n}=3$. $\left(\mathrm{Ct}=\right.$ cycle threshold, $\Delta=$ delta, $\left.2^{\wedge}=\log 2\right)$. stability of the hydrogel containing $\mathrm{NC}$ in comparison with CS/GP-21 containing a similar CS to GP ratio may likely be due to the increase in cross-linking density and lower weight loss which prolonged degradation endurance. It may be also attributed to the adsorption of $\mathrm{NC}$ on the surface of the hydrogel creating a protective coat that consolidated the scaffold and slowed down its degradation.

Gelation properties are indicative of the time frame for proper handling of thermosensitive hydrogel injection into the joint. ${ }^{18}$ The gelation time for CS/GP scaffolds was found to be in the range of 1.8-5.5 minutes and was significantly affected by the ratio of CS to GP (Figure 1B). Increasing the concentration of CS resulted in faster gelation which may be due to an increased number of CS-CS chain entanglements. ${ }^{36}$ The addition of NC to mixtures of CS/GP at 2:25 w/w ratio slightly decreased its gelation time to 2.8 minutes at $\mathrm{pH} 7.4$ which may be due to the increase in the rate of polymer chain dehydration and the interaction between the polymer chains leading to faster gelation.

The results of hydrogel swelling in aqueous solution showed an increase in swelling upon increasing the CS to GP ratio. The swelling behavior of the hydrogel depends on the intertwining, overlap and adsorption of the polymer chains. In this process, water diffuses into the polymer network, the hydrated polymer chains relax, and the polymer scaffold expands. The higher the crosslinking extent of a particular hydrogel is, the lower the extent of the gel swelling. The swelling ability of hydrogels in biological conditions allows the attachment and growth of cells, diffusion of nutrients, making them very similar to natural tissues. According to the gel degradation and gelation time, NC-CS/GP-21 should exhibit a lower Qm as compared to CS/GP-21 containing similar CS/GP ratio. However, NC-CS/GP-21 showed a significant increase in swelling which may be due to its high water absorbency and water retention. ${ }^{37}$

The obtained SEM micrographs for both CS/GP-21 and NC-CS/GP-21 hydrogel scaffolds showed a diversified, 
highly porous microstructure with pore size in the range of $100-400 \mu \mathrm{m}$. It was noticed that hydrogels containing $\mathrm{NC}$ had a smoother surface which may be due to the formation of thin NC coat adsorbed on the surface of the CS chains, with no significant effect on the pore size and geometry. Materials used for generation of the hydrogel scaffolds should mimic the morphology and structure of extracellular matrix in the native tissue to promote cell growth. The presence of pores in the hydrogel scaffold is essential for effective $3 \mathrm{D}$ cell culture. Pores are responsible for cell infiltration, new tissue ingrowth, nutrient diffusion, vascularization and metabolic waste elimination. ${ }^{38}$ Earlier studies showed that scaffolds with average pore size around $300 \mathrm{~nm}$ can significantly promote neovascularization, cell proliferation, chondrogenic gene expression, cartilage-like matrix deposition, and resulting bulk compressive modulus after in vitro culture. ${ }^{39-41}$

The rheological behavior of hydrogels is of great importance, since it affects viscoelasticity, injectability, tolerability, and in cell encapsulation. The decrease in viscosity of the hydrogel solution with increasing shear rate indicates shear-thinning behavior which is essential to facilitate the injectability of the cell-laden thermosensitive hydrogel solution. The increase in viscosity upon increasing the temperature is due to the interaction between the polymer chains resulting in the formation of a threedimensional structure. ${ }^{42}$ The higher viscosity showed by $\mathrm{NC}-\mathrm{CS} / \mathrm{GP}-21$ is an indication that the addition of $\mathrm{NC}$ increased the rigidity of the hydrogel at $37^{\circ} \mathrm{C}$ which can improve the mechanical strength of the scaffold required during the differentiation of the stem cells. An important factor to be considered in selecting a hydrogel scaffold for cartilage regeneration is their ability to provide a mechanically stable structure that can immobilize their load of stem cells for successful chondrogenesis. Along with suitable injectability to use it in any geometricalshaped defect, gelation of a cell-laden thermosensitive hydrogel should occur within a suitable time at physiological temperature to prevent infiltration of its cell load into surrounding tissues. Moreover, the gel exhibits a porous structure that allows cell growth and an optimum swelling behavior that allows permeation of nutrients and growth factors essential for stem cell growth and differentiation. ${ }^{43}$ The prepared NC-CS/GP-21 hydrogel can fulfill these conditions. Our in vivo results confirmed our in vitro findings and showed the morphological stability of the NC-CS/GP-21 hydrogel with embedded hDPSCs for 21 days after subcutaneous injections. This can lead to retention at the site of injection allowing enough time to achieve the desired effects. Cytotoxicity of the NC-CS /GP-21 hydrogel was tested on both hDPSCs and BMSCs for a period of 21 days and the results were encouraging with a cell viable percentage of $75 \pm 4.9 \%$ and $85 \pm 6.5 \%$, respectively. Both types of stem cells were used at passage 3 in the present study. The lower cell viability demonstrated by hDPSCs could be attributed to the fact that hDPSCs are considered relatively immature and undifferentiated when compared to other types of stem cells, as these cells are isolated from the dental pulp which is regarded as an embryonic-like tissue. It has been reported that hDPSCs reach the highest viability at passage 9 , whereas several other adult stem cell types reach their optimal viability at passages 3-6. Accordingly, these cells require a prolonged adaptive period to reach optimal viability. $^{44}$

Selecting the appropriate cell source to be seeded into an ideal biomaterial has always been a challenge in tissue regeneration approaches. In this study, hDPSCs were successfully isolated from adult wisdom teeth and expanded in culture. The stemness of the isolated cell populations was confirmed by the expression of CD44, CD90 and CD106 and negative expression of CD11b and CD45 surface markers. This immune-phenotypic analysis was compared with that of BMSCs which produced similar results. In addition to the privilege of obtaining hDPSCs noninvasively, these neural crest-derived stem cells have shown higher self-renewal capacity, immunomodulatory capability, differentiation into several cell types both in vitro and in vivo, and higher in vitro proliferation when compared to other stem cells. ${ }^{45-47}$ The immunomodulatory capacity was demonstrated in this study by the rapid resolution of the acute inflammatory reaction at the surgical site following the implantation procedure as well as the lack of infection. hDPSCs are isolated from impacted third molar teeth which are often indicated for extraction, and which contain the youngest pulp compared to other teeth. Another potentiality of hDPSCs is their ability to promote a high degree of vascularization, which is critical for the process of regeneration. ${ }^{48}$ In the present study, the chondrogenic differentiation potential of hDPSCs in NC-CS/GP-21 hydrogel was proved using histological and immunohistochemical analyses, and realtime PCR and was shown to be similar to BMSCs which is considered a standard cell source in tissue engineering.

The successful use of hDPSCs in various tissue regeneration applications has been attributed to their capacity to produce and secrete a wide array of cytokines and growth 
factors that play significant roles in the regeneration process, and their ability to stimulate the differentiation of endogenous stem cells at the site of their application. ${ }^{49} \mathrm{hDPSCs}$ have been reported to have higher angiogenic potential and higher level of immunosuppressive activities compared to BMSCs. ${ }^{6}$ Also, it has been shown that hDPSCs release antiinflammatory molecules, resulting in tissue survival. ${ }^{50}$ In the present study, both the in vitro and in vivo results confirmed the previous findings. Similar in vitro results were reported for the chondrogenic differentiation of hDPSCs on the chitosan-xanthan porous matrix scaffolds, ${ }^{51}$ and their osteogenic differentiation in injectable thermo-sensitive chitosan/b-glycerophosphate/hydroxyapatite hydrogel, ${ }^{52}$ and poly ( $N$-isopropylacrylamide) (PNIPAAm)-based copolymer/graphene oxide composite hydrogel with different feed ratios to chitosan. ${ }^{53}$ In the present study, the 3D cell construct was injected in the animal, and the host responded with an immune response that demonstrated a positive impact on the biomaterial microenvironment. This immune response was in the form of an acute inflammatory reaction, which was observed histologically as well as clinically, then resolved quickly by the end of the first week. This response must have attracted macrophages that, in parallel to hDPSCs, secreted growth factors and cytokines which are expected to support the regenerative activity. The use of nanofibrils to construct a hydrogel scaffold that acts together with stem cells for tissue regeneration is a cost-efficient strategy due mainly to the availability of the required biomaterials and the ease of production. However, the main challenge that might hinder the translation to clinical settings remains the antigenicity of the utilized cells and biomaterials that might trigger the body's immunogenic response. ${ }^{54}$ These obstacles have been overcome in the present study, as the biocompatibility of the construct has been proved in vitro as well as in vivo. Further studies will be required to provide the intra-articular functional evidence of the construct.

In summary, the proposed nanocellulose-based thermosensitive hydrogels can be considered as viable scaffolds for the in vitro and in vivo chondrogenesis of hDPSCs. Being derived from natural components and prepared in an aqueous environment conveyed unique characteristic properties to the hydrogel scaffolds such as biocompatibility, biodegradability and nontoxicity. In addition, they exhibited appropriate mechanical strength and can fill the defects by a simple in situ injection. The uniquely well-controlled physichochemical and mechanical properties of the prepared hydrogel scaffolds are well positioned to satisfy the diverse biomaterial requirements. This study adds to the array of translational research that focuses on the production of promising scaffold materials for specific soft-tissue engineering applications.

\section{Conclusions}

Nanocellulose-chitosan thermosensitive hydrogel is a biocompatible, injectable, mechanically stable and slowly degradable scaffold, which is suitable for cartilage regeneration. hDPSCs embedded in NC-CS/GP-21 hydrogel showed a proliferative capacity similar to BMSCs, while retaining the advantage of being isolated noninvasively from extracted teeth. Our results suggest that hDPSCs embedded in NC-CS/GP-21 hydrogel is a promising, minimally invasive, stem cell-based strategy for the regeneration of TMJ cartilage. Further studies are required to verify whether the use of NC-CS/GP-21 hydrogel as a scaffold for autologous cell transplantation would be an effective strategy for cartilage regeneration. An optimum translational approach would involve the use of a suitable scaffold to accommodate native cells allowing the remodeling and regeneration of damaged cartilage.

\section{Acknowledgments}

This research was funded by University of Sharjah, grant number 1701100124-P (principal investigator: Wael Talaat) and Aljalila Foundation Grant number AJF201777 (principal investigator: Mohamed Haider). The funding institutions had no involvement in any of the stages of the study.

\section{Disclosure}

The authors declare that they have no conflicts of interest for this work.

\section{References}

1. Abou Neel EA, Chrzanowski W, Salih VM, Kim HW, Knowles JC. Tissue engineering in dentistry. $J$ Dent. 2014;42(8):915-928. doi:10.1016/j.jdent.2014.05.008

2. Park IK, Cho CS. Stem cell-assisted approaches for cartilage tissue engineering. Int J Stem Cells. 2010;3(2):96-102. doi:10.15283/ ijsc.2010.3.2.96

3. Bailey MM, Wang L, Bode CJ, Mitchell KE, Detamore MS. A comparison of human umbilical cord matrix stem cells and temporomandibular joint condylar chondrocytes for tissue engineering temporomandibular joint condylar cartilage. Tissue Eng. 2007;13 (8):2003-2010. doi:10.1089/ten.2006.0150

4. Wang L, Tran I, Seshareddy K, Weiss ML, Detamore MS. A comparison of human bone marrow-derived mesenchymal stem cells and human umbilical cord-derived mesenchymal stromal cells for cartilage tissue engineering. Tissue Eng - Part A. 2009;15 (8):2259-2266. doi:10.1089/ten.tea.2008.0393 
5. Farshid G, Awad A, Beverley F, Leddy Holly A, Gimble Jeffrey M. Adipose-derived adult stem cells for cartilage tissue engineering. Biorheology. 2004;41(3-4):389-399.

6. Song M, Lee JH, Bae J, Bu Y, Kim EC. Human dental pulp stem cells are more effective than human bone marrow-derived mesenchymal stem cells in cerebral ischemic injury. Cell Transplant. 2017;26 (6):1001-1016. doi:10.3727/096368916X694391

7. Abukawa H, Terai H, Hannouche D, Vacanti JP, Kaban LB, Troulis MJ. Formation of a mandibular condyle in vitro by tissue engineering. J Oral Maxillofac Surg. 2003;61(1):94-100. doi:10.1053/joms.2003.50015

8. Terraciano V, Hwang N, Moroni L, et al. Differential response of adult and embryonic mesenchymal progenitor cells to mechanical compression in hydrogels. Stem Cells. 2007;25(11):2730-2738. doi:10.1634/stemcells.2007-0228

9. Lin N, Dufresne A. Nanocellulose in biomedicine: current status and future prospect. Eur Polym J. 2014;59:302-325. doi:10.1016/j. eurpolymj.2014.07.025

10. Molinaro G, Leroux J-C, Damas J, Adam A. Biocompatibility of thermosensitive chitosan-based hydrogels: an in vivo experimental approach to injectable biomaterials. Biomaterials. 2002;23 (13):2717-2722. doi:10.1016/S0142-9612(02)00004-2

11. Hastings CL, Kelly HM, Murphy MJ, Barry FP, O'Brien FJ, Duffy GP. Development of a thermoresponsive chitosan gel combined with human mesenchymal stem cells and desferrioxamine as a multimodal pro-angiogenic therapeutic for the treatment of critical limb ischaemia. J Control Release. 2012;161(1):73-80. doi:10.1016/ j.jconrel.2012.04.033

12. Zhou HY, Jiang LJ, Cao PP, Li JB, Chen XG. Glycerophosphatebased chitosan thermosensitive hydrogels and their biomedical applications. Carbohydr Polym. 2015;117:524-536. doi:10.1016/j. carbpol.2014.09.094

13. Priya James H, John R, Alex A, Anoop KR. Smart polymers for the controlled delivery of drugs - a concise overview. Acta Pharm Sin B. 2014;4(2):120-127. doi:10.1016/j.apsb.2014.02.005

14. Ruel-Gariépy E, Chenite A, Chaput C, Guirguis S, Leroux JC. Characterization of thermosensitive chitosan gels for the sustained delivery of drugs. Int J Pharm. 2000;203(1-2):89-98. doi:10.1016/ S0378-5173(00)00428-2

15. Chenite A, Buschmann M, Wang D, Chaput C, Kandani N. Rheological characterisation of thermogelling chitosan/glycerol-phosphate solutions. Carbohydr Polym. 2001;46(1):39-47. doi:10.1016/ S0144-8617(00)00281-2

16. Tsai M-L, Chang H-W, Yu H-C, Lin Y-S, Tsai Y-D. Effect of chitosan characteristics and solution conditions on gelation temperatures of chitosan/2-glycerophosphate/nanosilver hydrogels. Carbohydr Polym. 2011;84(4):1337-1343. doi:10.1016/j.carbpol.2011.01.035

17. Supper S, Anton N, Boisclair J, et al. Chitosan/glucose 1-phosphate as new stable in situ forming depot system for controlled drug delivery. Eur J Pharm Biopharm. 2014;88(2):361-373. doi:10.1016/ j.ejpb.2014.05.015

18. Talaat WM, Haider M, Al Kawas S, Kandil NG, Harding DRK. Chitosan-based thermosensitive hydrogel for controlled drug delivery to the temporomandibular joint. J Craniofac Surg. 2016;27 (3):735-740. doi:10.1097/SCS.0000000000002588

19. Haider M, Hassan MA, Ahmed IS, Shamma R. Thermogelling platform for baicalin delivery for versatile biomedical applications. Mol Pharm. 2018;15(8):3478-3488. doi:10.1021/acs.molpharmaceut.8b00480

20. Steadman JR, Rodkey WG, Rodrigo JJ. Microfracture: surgical technique and rehabilitation to treat chondral defects. Clin Orthop Relat Res. 2001;391(391 SUPPL):S362-9. doi:10.1097/00003086-20011000100033

21. Talaat WM, Adel OI, Al Bayatti S. Prevalence of temporomandibular disorders discovered incidentally during routine dental examination using the Research Diagnostic Criteria for temporomandibular disorders. Oral Surg Oral Med Oral Pathol Oral Radiol. 2018;125 (3):250-259. doi:10.1016/j.oooo.2017.11.012
22. Nicodemus GD, Bryant SJ. The role of hydrogel structure and dynamic loading on chondrocyte gene expression and matrix formation. J Biomech. 2008;41(7):1528-1536. doi:10.1016/j.jbiomech.2008.02.034

23. Jackson JK, Letchford K, Wasserman BZ, Ye L, Hamad WY, Burt HM. The use of nanocrystalline cellulose for the binding and controlled release of drugs. Int J Nanomedicine. 2011;6:321-330. doi:10.2147/ijn.s16749

24. Villanova JCO, Ayres E, Carvalho SM, Patrício PS, Pereira FV, Oréfice RL. Pharmaceutical acrylic beads obtained by suspension polymerization containing cellulose nanowhiskers as excipient for drug delivery. Eur J Pharm Sci. 2011;42(4):406-415. doi:10.1016/j. ejps.2011.01.005

25. Wippermann J, Schumann D, Klemm D, Kosmehl H, Salehi-Gelani S, Wahlers T. Preliminary results of small arterial substitute performed with a new cylindrical biomaterial composed of bacterial cellulose. Eur $J$ Vasc Endovasc Surg. 2009;37(5):592-596. doi:10.1016/j.ejvs.2009.01.007

26. Mathew AP, Oksman K, Pierron D, Harmand MF. Fibrous cellulose nanocomposite scaffolds prepared by partial dissolution for potential use as ligament or tendon substitutes. Carbohydr Polym. 2012;87 (3):2291-2298. doi:10.1016/j.carbpol.2011.10.063

27. Bodin A, Concaro S, Brittberg M, Gatenholm P. Bacterial cellulose as a potential meniscus implant. J Tissue Eng Regen Med. 2007;1 (5):406-408. doi:10.1002/term.51

28. Xiong R, Lu C, Zhang W, Zhou Z, Zhang X. Facile synthesis of tunable silver nanostructures for antibacterial application using cellulose nanocrystals. Carbohydr Polym. 2013;95(1):214-219. doi:10.10 16/j.carbpol.2013.02.077

29. Fu L, Zhang Y, Li C, et al. Skin tissue repair materials from bacterial cellulose by a multilayer fermentation method. $J$ Mater Chem. 2012;22(24):12349-12357. doi:10.1039/c2jm00134a

30. Fu L, Zhou P, Zhang S, Yang G. Evaluation of bacterial nanocellulose-based uniform wound dressing for large area skin transplantation. Mater Sci Eng C. 2013;33(5):2995-3000. doi:10.10 16/j.msec.2013.03.026

31. Male KB, Leung ACW, Montes J, Kamen A, Luong JHT. Probing inhibitory effects of nanocrystalline cellulose: inhibition versus surface charge. Nanoscale. 2012;4(4):1373-1379. doi:10.1039/c2nr11886f

32. Czaja WK, Young DJ, Kawecki M, Brown RM. The future prospects of microbial cellulose in biomedical applications. Biomacromolecules. 2007;8(1):1-12. doi:10.1021/bm060620d

33. Saravanan S, Vimalraj S, Thanikaivelan $P$, Banudevi S, Manivasagam G. A review on injectable chitosan/beta glycerophosphate hydrogels for bone tissue regeneration. Int J Biol Macromol. 2019;121:38-54. doi:10.1016/j.ijbiomac.2018.10.014

34. Lin WC, Lien CC, Yeh HJ, Yu CM, Hsu SH. Bacterial cellulose and bacterial cellulose-chitosan membranes for wound dressing applications. Carbohydr Polym. 2013;94(1):603-611. doi:10.1016/j. carbpol.2013.01.076

35. Dang QF, Yan JQ, Li JJ, Cheng XJ, Liu CS, Chen XG. Controlled gelation temperature, pore diameter and degradation of a highly porous chitosan-based hydrogel. Carbohydr Polym. 2011;83 (1):171-178. doi:10.1016/j.carbpol.2010.07.038

36. Zhou HY, Chen XG, Kong M, Liu CS, Cha DS, Kennedy JF. Effect of molecular weight and degree of chitosan deacetylation on the preparation and characteristics of chitosan thermosensitive hydrogel as a delivery system. Carbohydr Polym. 2008;73(2):265-273. doi:10.1016/j.carbpol.2007.11.026

37. Tang A, Wang Q, Zhao S, Liu W. Fabrication of nanocellulose/ PEGDA hydrogel by 3D printing. Rapid Prototyp J. 2018;24 (8):1265-1271. doi:10.1108/RPJ-03-2016-0049

38. Hollister SJ. Porous scaffold design for tissue engineering. Nat Mater. 2005;4(7):518-524. doi:10.1038/nmat1421

39. Im GI, Ko JY, Lee JH. Chondrogenesis of adipose stem cells in a porous polymer scaffold: influence of the pore size. Cell Transplant. 2012;21(11):2397-2405. doi:10.3727/096368912X638 865 
40. Matsiko A, Gleeson JP, O’Brien FJ. Scaffold mean pore size influences mesenchymal stem cell chondrogenic differentiation and matrix deposition. Tissue Eng - Part A. 2015;21(3-4):486-497. doi:10.1089/ ten.tea.2013.0545

41. Nava MM, Draghi L, Giordano C, Pietrabissa R. The effect of scaffold pore size in cartilage tissue engineering. $J$ Appl Biomater Funct Mater. 2016;14(3):e223-e229. doi:10.5301/jabfm.5000302

42. Lavanya K, Chandran SV, Balagangadharan K, Selvamurugan N. Temperature- and $\mathrm{pH}$-responsive chitosan-based injectable hydrogels for bone tissue engineering. Mater Sci Eng C. 2020;111:110862. doi:10.1016/j.msec.2020.110862

43. Chenite A, Chaput C, Wang D, et al. Novel injectable neutral solutions of chitosan form biodegradable gels in situ. Biomaterials. 2000;21(21):2155-2161. doi:10.1016/S0142-9612(00)00116-2

44. Martin-Piedra MA, Garzon I, Oliveira AC, et al. Average cell viability levels of human dental pulp stem cells: an accurate combinatorial index for quality control in tissue engineering. Cytotherapy. 2013;15 (4):507-518. doi:10.1016/j.jcyt.2012.11.017

45. Gronthos S, Mankani M, Brahim J, Robey PG, Shi S. Postnatal human dental pulp stem cells (DPSCs) in vitro and in vivo. Proc Natl Acad Sci US A. 2000;97(25):13625-13630. doi:10.1073/pnas.240309797

46. Inoue T, Sugiyama M, Hattori H, Wakita H, Wakabayashi T, Ueda M. Stem cells from human exfoliated deciduous tooth-derived conditioned medium enhance recovery of focal cerebral ischemia in rats. Tissue Eng Part A. 2013;19(1-2):24-29. doi:10.1089/ten.tea.2011.0385

47. Pierdomenico L, Bonsi L, Calvitti M, et al. Multipotent mesenchymal stem cells with immunosuppressive activity can be easily isolated from dental pulp. Transplantation. 2005;80(6):836-842. doi:10.1097/ 01.tp.0000173794.72151.88

48. Iohara K, Zheng L, Wake $\mathrm{H}$, et al. A novel stem cell source for vasculogenesis in ischemia: subfraction of side population cells from dental pulp. Stem Cells. 2008;26(9):2408-2418. doi:10.1634/stemcells.2008-0393
49. Matsushita K, Motani R, Sakuta T, et al. The role of vascular endothelial growth factor in human dental pulp cells: induction of chemotaxis, proliferation, and differentiation and activation of the AP-1-dependent signaling pathway. J Dent Res. 2000;79(8):15 96-1603. doi:10.1177/00220345000790081201

50. Nosrat IV, Widenfalk J, Olson L, Nosrat CA. Dental pulp cells produce neurotrophic factors, interact with trigeminal neurons in vitro, and rescue motoneurons after spinal cord injury. Dev Biol. 2001;238(1):120-132. doi:10.1006/dbio.2001.0400

51. Westin CB, Trinca RB, Zuliani C, Coimbra IB, Moraes ÂM. Differentiation of dental pulp stem cells into chondrocytes upon culture on porous chitosan-xanthan scaffolds in the presence of kartogenin. Mater Sci Eng C Mater Biol Appl. 2017;80:594-602. doi:10.1016/j.msec.2017.07.005

52. Chen Y, Zhang F, Fu Q, Liu Y, Wang Z, Qi N. In vitro proliferation and osteogenic differentiation of human dental pulp stem cells in injectable thermo-sensitive chitosan/ $\beta$-glycerophosphate/hydroxyapatite hydrogel. J Biomater Appl. 2016;31(3):317-327. doi:10.1177/ 0885328216661566

53. Amiryaghoubi N, Noroozi Pesyan N, Fathi M, Omidi Y. Injectable thermosensitive hybrid hydrogel containing graphene oxide and chitosan as dental pulp stem cells scaffold for bone tissue engineering. Int J Biol Macromol. 2020;162:1338-1357. doi:10.1016/j.ijbiomac. 2020.06.138

54. Chan KH, Lee WH, Zhuo S, Ni M. Harnessing supramolecular peptide nanotechnology in biomedical applications. Int $J$ Nanomedicine. 2017;12:1171-1182. doi:10.2147/IJN.S126154
International Journal of Nanomedicine

\section{Publish your work in this journal}

The International Journal of Nanomedicine is an international, peerreviewed journal focusing on the application of nanotechnology in diagnostics, therapeutics, and drug delivery systems throughout the biomedical field. This journal is indexed on PubMed Central, MedLine, CAS, SciSearch ${ }^{\circledR}$, Current Contents ${ }^{\circledR} /$ Clinical Medicine,
Journal Citation Reports/Science Edition, EMBase, Scopus and the Elsevier Bibliographic databases. The manuscript management system is completely online and includes a very quick and fair peer-review system, which is all easy to use. Visit http://www.dovepress.com/ testimonials.php to read real quotes from published authors. 